\title{
Effects of soya bean meal feed properties on extrusion failures and implementing a solution. Case study Monmouth Path's Investments (Pvt) Ltd, Harare, Zimbabwe
}

\author{
P. Muredzi ${ }^{1}$, M. Nyahada $^{2}$, B.W. Mashswa ${ }^{2}$ \\ ${ }^{1}$ School of Industrial Sciences and Technology, Harare Institute of Technology, Ganges Rd, Belvedere, Harare, Zimbabwe \\ ${ }^{2}$ Department of Food Processing Technology, Harare Institute of Technology, Ganges Rd, Belvedere, Harare, Zimbabwe
}

Email address:

pmuredzi@hit.ac.zw (P. Muredzi), mnyahada@hit.ac.zw (M. Nyahada),bwmashwa@hit.ac.zw (B.W. Mashswa)

\section{To cite this article:}

P. Muredzi, M. Nyahada, B.W. Mashswa. Effects of Soya Bean Meal Feed Properties on Extrusion Failures and Implementing a Solution. Case Study Monmouth Path's Investments (Pvt) Ltd, Harare, ZimBabwe, International Journal of Nutrition and Food Sciences. Vol. 2, No. 2, 2013, pp. 60-69. doi: 10.11648/j.ijnfs.20130202.16

\begin{abstract}
This research was a contribution on the optimization of extrusion process by determining the effects of feed properties on extrusion failures and implementing a solution. The objectives of the research were to increase the set soy meal to chunk conversion standard from $65 \%$ to $80 \%$; to determine the effects of feed properties on extrusion failures; to determine the best conditions of the feed properties that promote an effective extrusion cooking process; and to determine a solution of optimizing these feed properties for successful extrusion. The research was company based and it followed the failures of extrusion experienced at Monmouth Path Investment (Pvt) Ltd in Waterfall, Harare. This research was limited to feed properties such as fat content, moisture content and particle size as the factors that cause extrusion failures. The determination of moisture content was done by using a moisture analyzer, fat content was determined through the Soxhlet method and the particle size of the feed was determined through sieve analysis. The results revealed that extrusion process was most successful when the soy meals fat content was greater than $6.0 \%$, with a moisture content less than $6.0 \%$ and particle size range of $0.95-1.0 \mathrm{~mm}$. The process of optimization of extrusion process was solved by designing an extrusion calculator and blending ratio factors. The objective of determining the effects of feed properties on extrusion failures was achieved as well as that of implementing a solution. The objective of increasing Monmouth Path's standard soy meal/chunk conversion was partially achieved since the implemented solution is not yet measurable.
\end{abstract}

Keywords: Extrusion; Feed Material; Feed Rate, Soy Meal Size; Moisture Content; Correlation

\section{Introduction}

Extrusion is a process of central importance and widespread application in the food industry in Zimbabwe. The extensive development of extrusion technology represents one of the most significant achievements in food process engineering in the last fifty years. Extrusion is done in the production of such products as expanded snacks, ready-to-eat cereals, pellets and texturized proteins products for example, soy chunks (which is the main focus of this research). This research was focused on the evaluation of the factors that cause extrusion failures and the implementation of a solution.

The research was industrial based for a company called Monmouth Path Investment (Pvt) Ltd located in Waterfall.
The company's prime raw material is soybeans and it is processed into soy based products (cooking oil, soy chunks and oil). One of the main problems this company was facing was that of failures in chunk extrusion. They believed it was caused by the feed properties and according to literature extrusion failures are caused by feed properties and extrusion parameters (www.extrusionfactors.edu). Monmouth's source of income is mainly boosted by soy chunks and their set standard soy meal conversion to chunks per each production batch is $65 \%$. Considering the fact that soybeans cannot be grown all year round in Zimbabwe therefore any failures on chunk production will result in a depreciation of funds throughout the phases of the end season. The company's probability of sustenance went down as 0.30 in November and in December and considering the fact that the 
company has experienced losses of approximately $60 \%$ due to extrusion failures since it was founded. If such operation losses continue the company is likely to collapse in the long run.

The aim of the research was to investigate on the effect of feed properties on extrusion failures and implementing a solution. The objectives of the research were to increase the set soy meal to chunk conversion standard from $65 \%$ to $80 \%$; to determine the effects of feed properties on extrusion cooking process; to determine the best conditions of the feed properties that promote an effective extrusion cooking process; and to design a device that will help to optimize these feed properties for successful extrusion process. The research was done in the favour of Monmouth as way of increasing its extrusion success operations.

This research was limited to fat, moisture content tests and size of feed particles, physical extrusion operation parameter (feed rate) and not on soybean varieties and the chemistry behind.

\section{Extrusion}

The verb "to extrude" derives from Latin word ex (out) and trudere (to thrust), and means to force, as through a small opening or to shape a material under pressure by forcing it through a specially designed opening [4] or Ex- trusion cooking is a high-temperature, short-time process in which moistened, expansive, starchy and/or protenacious food materials are plasticized and cooked in a tube by a combination of moisture, pressure, temperature and mechanical shear, resulting in molecular transformation and chemical reactions (Havck\& Huber, 1989; Castells et al., 2005).

Extrusion is done by an extruder which is a machine which shapes materials or a thermostatically controlled cylinder or conical body which contains a polished, rotating screw with a gradually decreasing pitch. According to Harper (1979), [3] a food extruder consists of a flighted Archimedes screw, which rotates in a tightly fitting cylindrical barrel. Raw ingredients are pre-ground and blended before being placed in the feeding system of the extrusion screw. The action of the flights on the screw push the food products forward and in so doing, work and mix the constituents into viscous dough-like mass.

There are two main types of extruders namely single screw extruders and twin-screw extruders (co-rotating and counter rotating). At Monmouth Path they use single screw extruders and these extruders they only have one parameter of control and that is feed rate. The screw seed remains constant and the temperature that is friction generated [14].

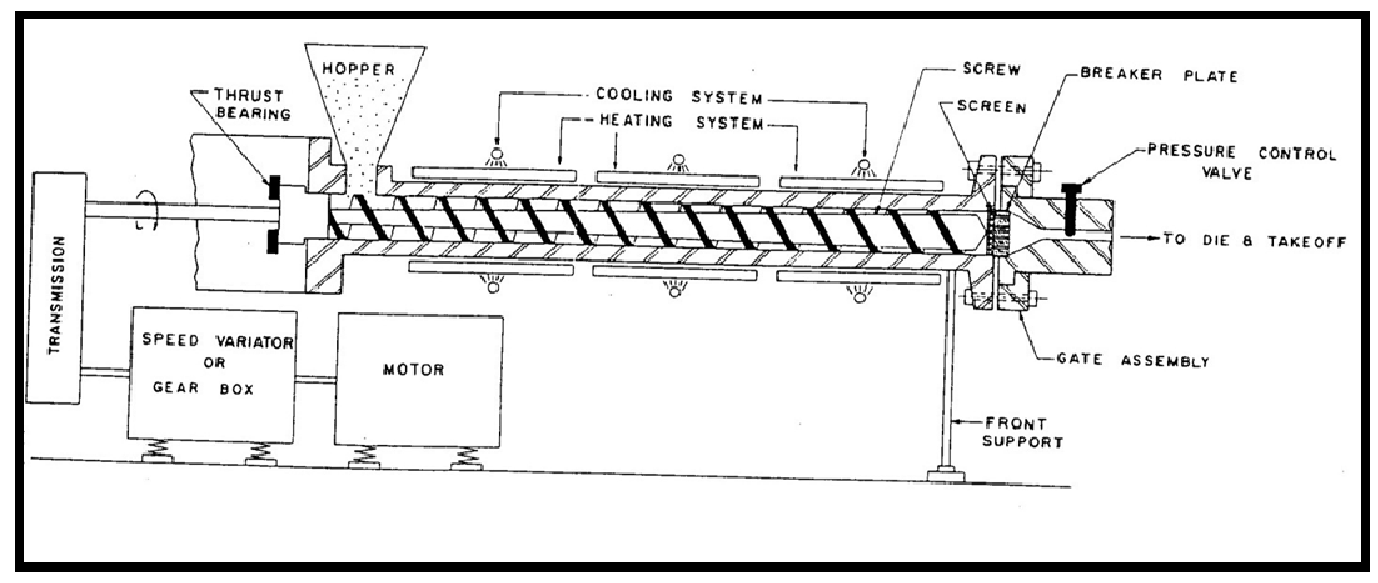

Figure 1. Single Screw Extruder.

Extrusion cooking is a continuous process by which food biopolymers and ingredients are mixed, plasticized, cooked and formed by combination of moisture, temperature, pressure, and mechanical shear. The extrusion-cooking process combines the effect of heat with the action of extrusion [5] All combinations that promote the occurrence of extrusion can however affect the rate of extrusion if they are not attained, for example, because of the temperature and moisture conditions in this extrusion process a post die expansion of extrudate takes place resulting in a light and crispy product (Harper, 1979).

Extrusion cooking process is affected by two classified groups of factors which are:

Feed properties

Moisture Content

Moisture is one of the key factors that affect extrusion cooking, lowering water content of the feed material (soy meal) results in higher viscosity, which causes throughput rate to decrease, pressure drop to increase, and power consumption to increase. However, in extrusion of starch, gelatinization occurs more readily at higher moisture contents. Soybeans are harvested at 11 to $13 \%$ moisture content and can be placed directly into ordinary storage bins equipped with simple aeration systems [www.soybeans.umn.edu]. A modern way of obtaining moisture content is by using a moisture content analyzer.

Type of Feed Properties

The type and nature of feed material, in term of protein, starch, lipid, and moisture plays a significant role on the nature of extruded products. In addition to differences in viscosity between materials made from different grains, the internal structure of the extruded products is also caused by 
different constituents. For example, adding whey proteins to grain-type extruded products will significantly alter the gel structure during extrusion cooking and, hence a different product exiting the die [www.extrusionfactors.edu].

$\mathrm{pH}$ of Ingredients

Adjusting the $\mathrm{pH}$ of the feed material may influence the state of proteins during extrusion and thus influence physical characteristics of the final product. Study has shown that increasing $\mathrm{pH}$ in the 5.5-7.5 range results in an increase in volatile compounds in cystein/reducing sugar/starch mixture during extrusion. Both higher and lower $\mathrm{pH}$ values caused reduction in tensile strength. Changing $\mathrm{pH}$ may also cause changes in color and nutritional content of extruded products [www.extrusionfactors.edu].

Particle size of feed materials

Starch having particle size greater than 14 mesh will not be readily gelatinized. Small particles (40-120 mesh) are more easily hydrated and cooked than larger particles [www.extrusionfactors.edu].

Constituencies of feed material

Ingredients such as oil and emulsifier may also be added to the feed material to decrease viscosity of the raw material. This also helps lubricate the extrusion cooking process of such material and decrease the amount of viscous heat dissipation [www.extrusionfactors.edu]. One of the factors that affect extrusion cooking process is oil content within the sample. It is usually important for a sample to have at most an average oil content of $6.5-8.5 \%$ prior to extrusion (www.soybeans.umn.edu). To determine this oil content within a sample, a Soxhlet apparatus is used.

Considering the main causes in failures of soybean extrusion this research was limited on four of the five factors of feed properties that affects extrusion and these include moisture content, size of particles, constituents of feed material (in terms of fat content) and type of feed material.

Extruder Operating Parameters

Type of Extruder

Typically, a single-screw extruder is the best choice for simple products. However, a single-screw extruder provides limited flexibility for new and unique products. Twin-screw extruders are able to provide multiple processing steps (i.e., kneading, mixing). They also produce higher production rates [www.extrusionfactors.edu].

Feed Rate

Feed rates are normally kept low enough that the extruder operates under starved-fed conditions. That is, the flights of the screw in the feed section are not completely filled. As the screw root diameter is increased in the transition zone and the channel size is reduced, the screw becomes completely filled as material enters the metering zone [www.extrusionfactors.edu].

\section{Screw Geometry}

In a single-screw extruder, parameters that can be adjusted include the pitch of the screw, the diameter of the screw, and the clearance between the top of the flight and the barrel, and the number of flights on the screw. For a twin-screw extruder, the options for screw geometry and range of configurations are numerous. Parameters that can be varied in a twin-screw extruder include pitch of the screw, number of flights, root diameter, angle of pitch of the screw, degree of intermeshing of the two screws, and the type of mixing device (www.extrusionfactors.edu).

Screw Speed

Screw speed affects the degree of fill within the screw, residence time distribution of product flowing through the extruder, heat transfer rates and mechanical energy input in the extruder, and the shear forces exerted on the materials. Screw speed typically falls in the range of 100-500rpm.The normal minimum screw speed range is 70-100 rpm. Below this, the volumetric capacity would be severely limited and make the majority of food extrusion products costly to manufacturers. Most manufacturers chose to run at the maximum speeds mechanically tolerable, usually 400-500 rpm [www.extrusionfactors.edu].

Barrel Temperature

The frictional heat generation requires the barrel to be cooled with air or water. Extrudate temperature can reach $180^{\circ} \mathrm{C}$. In order to prevent material from burning on the hot barrel surface, or inhibit excessive maillard browning, or limit the degree of protein denaturation, the barrel jacket can be fed with chilled water. Reducing temperature in the material can also be done by increasing water or oil content or reducing the degree of shear, which can be done by reducing the screw speed or the severity of the screw configuration.

\section{Methodology}

Data collection of the research was done in two forms classes namely primary and secondary data.

Primary Data

This data was obtained from the field by the use of experiments and brainstorming. Experiments which were conducted included the determination of moisture content and fat content in the soy bean and soy meal, the determination of water intake (rate) using a stop watch and average calculation of extrusion feed rate.

Secondary Data

This type of data that was collected from secondary sources such as records, journals, internet and books, for such a research like this the secondary data concerned techniques used to determine the content of fat and moisture.

The data was analysed both qualitatively and quantitatively. Scientific graphs and statistical techniques of analysis were used to analyse the soy constituencies, process conditions and parameters.

The mapping of this research was done through design models. The research followed two design models in coming up with a hybrid model to use. The two design processes in consideration are according to Hertz (2007) and Norman (1995) . These two design processes were selected taking into account the weaknesses and strengths of each model over the other.

Research Brief 
The purpose for the research was to evaluate the possible factors causing the failures in extrusion operation and implementing a solution. The research mainly concentrated on the feed properties such as moisture content, fat content and size of particles of the soy-meal as the factors that affect extrusion. Operating factors were not considered highly in this research since the type of extruders operating at Mon-Mouth has constant operation parameters except for the screw feed rate. The solution implemented to the problem was that of an extrusion calculator which was developed from the data analysis on the correlation between feed properties and feed rate.

Research Procedures

The procedures of data collection were done and results were produced experimentally. Corresponding feed rate and sample particle size were frequently collected, averaged and recorded. All the experimental procedures and measured parameters that followed the research design are as follows:

Determination of Moisture Content

The determination of moisture content within the soy meal was done by the use of a Moisture Analyzer. $5 \mathrm{~g}$ of the soymeal was measured and inserted in a moisture analyzer at a temperature of $110^{\circ} \mathrm{C}$. Results were obtained after $10 \mathrm{mins}$ per each sample.

Determination of Fat/Oil Content

The determination of the fat content within the soymeal followed the Soxhlet Extraction Method [Soxhlet, F; 1879 and William B, 2007]

Calculation

weightoffat $=$ weightofflask + fat-weightofemptyfat.

$\%$ content $=($ weightoffat $\times 100)$ /initialsampleweight $(5)$

Determination of Average Extrusion Feed Rate

Initial extrusion feed rate and any changes of the feed rate during processing were recorded. After the recording of all the extrusion feed rate values, an average was calculated and recorded on the results sheet.

Determination of Average Soy-meal Size

Size determination of the soy-meal was obtained through sieve analysis [1]

\section{Results}

\begin{tabular}{llllll}
\hline Date & $\begin{array}{l}\text { Soy -meal } \\
\text { Oil Content(\%) }\end{array}$ & $\begin{array}{l}\text { Soy-meal Moisture } \\
\text { Content }(\%)\end{array}$ & $\begin{array}{l}\text { Soy-meal Particle } \\
\text { Size }(\mathbf{m m})\end{array}$ & $\begin{array}{l}\text { Ex 2 Av Feed } \\
\text { Rate (rev/min) }\end{array}$ & Chunk Comment \\
\hline $04 / 11 / 11$ & 5.101 & 5.182 & 0.8 & 10.9 & Fair \\
$10 / 11 / 11$ & 6.22 & 5.954 & 1.0 & 12.2 & Good \\
$16 / 01 / 12$ & 4.8 & 5.627 & 0.8 & 9.4 & Fair \\
$17 / 01 / 12$ & 7.0 & 4.893 & 0.95 & 10.9 & Excellent \\
$19 / 01 / 12$ & 5.261 & 5.830 & 0.8 & 11.0 & Fair \\
$21 / 01 / 12$ & 4.901 & 5.232 & 0.8 & 10.5 & Poor \\
$24 / 01 / 12$ & 6.25 & 6.301 & 1.0 & 10.6 & Good \\
$25 / 01 / 12$ & 4.728 & 5.659 & 0.8 & 11.5 & Poor \\
$26 / 01 / 12$ & 5.635 & 4.496 & 0.9 & 12.4 & Fair \\
$27 / 01 / 12$ & 6.452 & 6.033 & 1.0 & 11.3 & Good \\
$02 / 02 / 12$ & 5.312 & 6.980 & 0.95 & 11.2 & Good \\
$06 / 02 / 12$ & 6.67 & 6.073 & 1.2 & 11.25 & Excellent \\
$08 / 02 / 12$ & 5.784 & 6.123 & 0.8 & 11.6 & Poor \\
$10 / 02 / 12$ & 6.342 & 6.032 & 1.0 & 11.1 & Excellent \\
$14 / 02 / 12$ & 5.476 & 6.062 & 0.8 & 11.8 & Poor \\
$16 / 02 / 12$ & 6.338 & 5.686 & 1.0 & 11.32 & Excellent \\
$24 / 02 / 12$ & 6.36 & 6.228 & 0.95 & 11.2 & Good \\
$28 / 02 / 12$ & 4.877 & 5.312 & 0.8 & 11.4 & Poor \\
\hline
\end{tabular}

\section{Results Analysis}

Results were obtained and an evaluation of the trend was done. It was observed that extrusion successes in production of good and excellent chunks were most prominent of those soy meal batches which had fat/oil content of $6.0 \%$ and above. According to the literature, oil is of importance since it helps in the lubrication of the extrusion cooking process and also decreases the amount of viscous heat dissipation. The results trend highlighted a common trend justifying that for extrusion to occur successfully the fat content had to be slightly above the moisture content. According to the literature, one of the factors that affect extrusion cooking process is oil content within the sample. It is usually important for a sample to have at most an average oil content of
$6.5-8.5 \%$ prior to extrusion [www.soybeans.umn.edu]. The results clearly highlighted that since most of the extrusion process was successful when the oil content was above $6.0 \%$ through the average range in mentioned above is slightly higher.

Since extrusion cooking occurs in the presence of injected water, the reason of having low moisture content in the soy meal than $6.0 \%$ was justified. The available literature only explained that soybeans are harvested at 11 to $13 \%$ moisture content which means that this research highlighted that moisture content from the point of soybeans is different to that of soy meal because through every stage of process from crushing till soy meal production moisture content is lost.

Conceptualization

The results led the research into design conceptualization. 
According to Hertz (2007), the third step of design is called conceptualization. At this stage designer considers the alternative concepts to find the best possible design to solution problem. The research was done considering two alternatives to implementing a solution.

Alternative one: Portable Extrusion Calculator

The first alternative was to design a portable extrusion calculator that can calculate the required feed rate of particular soy meal constituents. The design process will react in an open loop manner where the input data in the form of moisture content, fat content and particle size are fed in and transformed into feed rate. The fig diagram below illustrate an open loop model of the extrusion calculator

Dimensions of the extrusion calculator.

\begin{tabular}{ll}
\hline Length & $\mathbf{1 5 0} \mathbf{m m}$ \\
\hline Width & $75 \mathrm{~mm}$ \\
Height & $10 \mathrm{~mm}$ \\
Total Volume & $112.5 \mathrm{~cm}^{3}$ \\
\hline
\end{tabular}

The dimensions of the calculator support the reasoning that it is portable and can be carried around the plant at ease.

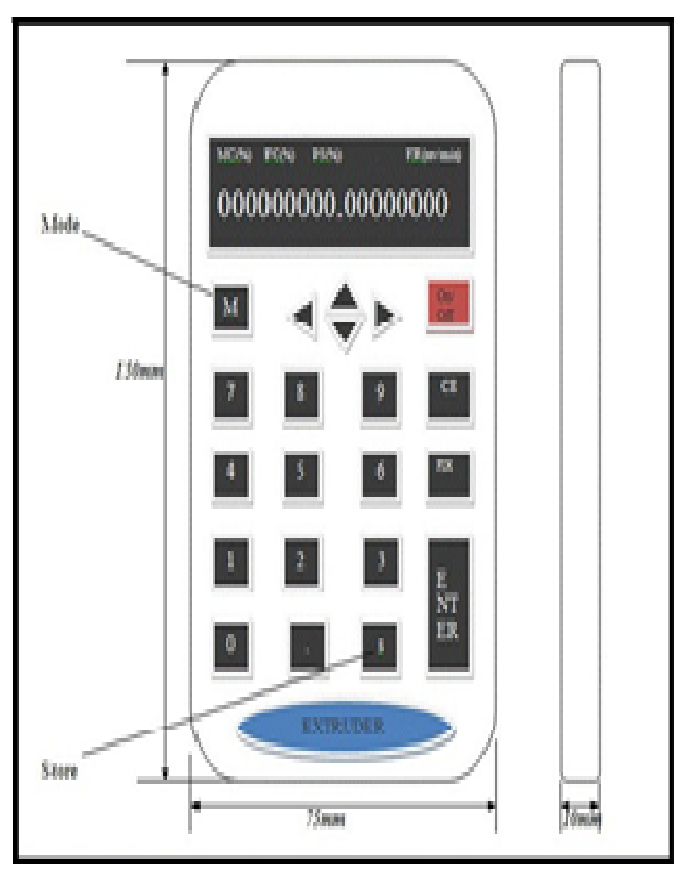

Figure 2. Extrusion Calculator Sketch.

\section{Principle of Operation}

The extrusion calculator is composed of many operations including the storage of data operation, calculation of feed rate from the moisture content (MC), fat content (FC) and particle size (PS), calculation of the soy meal mixing ratio if the soy constituents are at extremes and can be connected to a computer for data printing. From the calculator sketch model in fig 2, the $M$ in the far upper left side stands for
MODE. The mode button will assist in data entering process from one parameter to the next.

\section{Costing of the 1st Alternative}

\begin{tabular}{ll}
\hline Item & Amount (\$) \\
\hline Processor (PIC 16F/627) & 6.00 \\
Key pad & 7.00 \\
LCD Screen & 30.00 \\
Power Supply & 5.00 \\
$\begin{array}{l}\text { Rechargeable Battery } \\
\begin{array}{l}\text { Others (mother body, } \\
\text { resistors, software } \\
\text { encoding, housing etc.) }\end{array}\end{array}$ & 3.00 \\
\begin{tabular}{l} 
Total \\
\hline
\end{tabular}
\end{tabular}

\section{Alternative two: Extrusion Calculator Setup}

One of the most technological adoptions in many industries is the use of computers. This second alternative was a complementary model of alternative one but differs in the sense that the extrusion calculator will be in the form of a computer installation setup written on a DVD.

Costing of the 2nd Alternative

\begin{tabular}{ll}
\hline Item & Amount (\$) \\
\hline Software encoding & 15.00 \\
Rewritable Blank DVD (4.0 Gig) & 1.50 \\
CD Face Printing & 1.00 \\
Total & 17.50 \\
\hline
\end{tabular}

Concept Evaluation

Comparison of the two alternatives

\begin{tabular}{lll}
\hline Parameters & $\mathbf{1}^{\text {st }}$ Alternative & $\mathbf{2}^{\text {nd }}$ Alternative \\
\hline Manufacturing Cost & $\$ 76.00$ & $\$ 17.50$ \\
Maintenance Cost & High & Low \\
Effectiveness & Moderate & Moderate \\
Portability & Very portable & Not portable \\
\hline
\end{tabular}

The research adopted alternative two because of its low manufacturing cost and maintenance cost.

Detailed Research Design and Evaluation

Development of the detailed design alternative two began with analysis of data obtained in the results table to come up the functioning formula that enabled the optimum calculation of the feed rate.

Extrusion Calculator Formula Generation

Determination of a correlation between fat content and feed rate. 
Fat content against feed rate

\begin{tabular}{ll}
\hline Fc) FAT CONTENT $(\%)\left[\mathbf{x}_{1}\right]$ & $\begin{array}{l}\text { FEED RATE }(\mathrm{rev} / \mathbf{m i n}) \\
{[\mathrm{Y}]}\end{array}$ \\
\hline $\mathbf{5 . 1 0 1}$ & 10.9 \\
$\mathbf{6 . 2 2}$ & 12.2 \\
$\mathbf{4 . 8 0}$ & 9.4 \\
$\mathbf{7 . 0}$ & 10.9 \\
$\mathbf{5 . 2 6 1}$ & 11.0 \\
$\mathbf{4 . 9 0 1}$ & 10.5 \\
$\mathbf{6 . 2 5}$ & 10.6 \\
$\mathbf{4 . 7 2 8}$ & 11.5 \\
$\mathbf{5 . 6 3 5}$ & 12.4 \\
$\mathbf{6 . 4 5 2}$ & 11.3 \\
$\mathbf{5 . 3 1 2}$ & 11.2 \\
$\mathbf{6 . 6 7}$ & 11.25 \\
$\mathbf{5 . 7 8 4}$ & 11.6 \\
$\mathbf{6 . 3 4 2}$ & 11.1 \\
$\mathbf{5 . 4 7 6}$ & 11.8 \\
$\mathbf{6 . 3 3 8}$ & 11.32 \\
$\mathbf{6 . 3 6}$ & 11.2 \\
$\mathbf{4 . 8 7 7}$ & 11.4 \\
$\sum \mathbf{x}_{\mathbf{1}}=\mathbf{1 0 3 . 5 0 7}$ & $\sum \mathbf{y}=\mathbf{2 0 1 . 5 7}$ \\
\hline
\end{tabular}

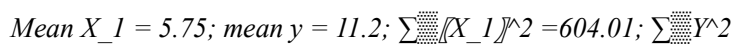
$=2264.6849 ; \sum$ W $\left[X \_1 Y\right]=1106.86$;

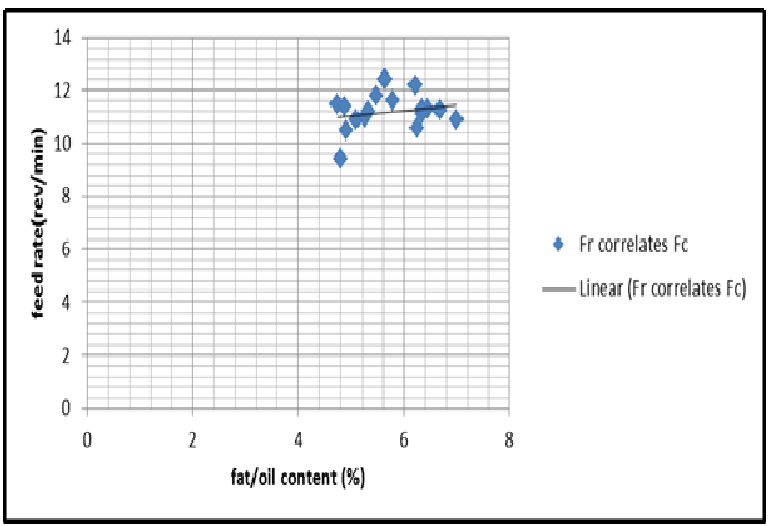

Figure 3. Correlation between fat content and feed rate

$$
\begin{gathered}
\text { s_(X_1 })=0.72 \text { and s_Y }=0.66 \\
r=s \_x y /\left(s \_x \text { s_y }\right) \\
r=0.0972 /((0.72 * 0.66)) \\
r=0.2043 \text { s.f. }
\end{gathered}
$$

The coefficient correlation between fat content and feed rate was 0.204 . Therefore a weak positive correlation existed between the fat content and feed rate.
To obtain the feed rate value only given the fat content the following regression linear correlation general formula was:

$$
\mathrm{Y}=\mathrm{a}+\mathrm{X} \_1 \mathrm{~b}
$$

Where: $\mathrm{Y}$ - feed rate

X 1 - fat content

And $\mathrm{a}$ and $\mathrm{b}$ - are constants

Where

$$
\mathrm{a}=10.1
$$

and

$$
b=0.199
$$

Hence the correlation formula was:

$$
\mathrm{Y}=10.1+0.199 \mathrm{X} \_1
$$

Determination of correlation between moisture content and feed rate

Moisture content against feed rate.

\begin{tabular}{ll}
\hline Mc) moisture content $(\%)\left[\mathbf{x}_{2}\right]$ & $(\mathbf{f r})$ feed rate $(\mathbf{r e v} / \mathbf{m i n})[\mathbf{y}]$ \\
\hline 5.182 & 10.9 \\
5.954 & 12.2 \\
5.627 & 9.4 \\
4.893 & 10.9 \\
5.83 & 11.0 \\
5.232 & 10.5 \\
6.301 & 10.6 \\
5.659 & 11.5 \\
4.496 & 12.4 \\
6.033 & 11.3 \\
6.98 & 11.2 \\
6.073 & 11.25 \\
6.123 & 11.6 \\
6.032 & 11.1 \\
6.062 & 11.8 \\
5.686 & 11.32 \\
6.228 & 11.2 \\
5.312 & $\mathrm{y}=201.57$ \\
$\sum \mathrm{x}_{2}=103.703$ & $6 x 27.4$ \\
\hline & \\
\hline
\end{tabular}

Mean $X \_2=5.76$; mean $Y=11.2 ; \sum \sum\left[X_{-} 2 \rrbracket^{\wedge} 2=603.017 ; \sum \sum{ }^{\wedge}{ }^{\wedge} 2\right.$ $=2264.6849 ; \sum$ 器 $\left[X \_2 Y=1106.86\right.$; 


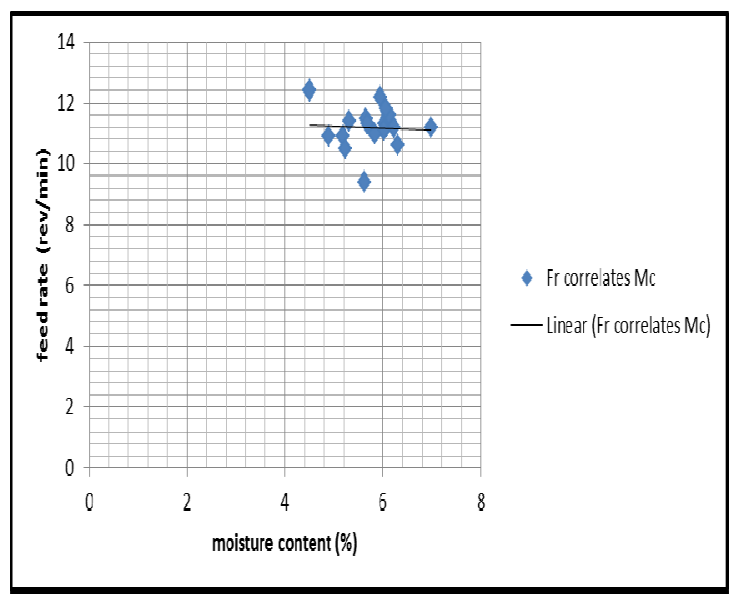

Figure 4. Correlation between moisture content and feed rate

$$
\begin{gathered}
\text { s_(X_2 })=0.58 \text { and s_Y }=0.66 \\
r=s \_x y /\left(s \_x \text { s_y }\right) \\
r=(-0.0226) /\left(\left(0.58^{*} 0.66\right)\right) \\
r=-0.05903 \text { s.f. }
\end{gathered}
$$

The coefficient correlation between moisture content and feed rate was- 0.0590 . Therefore a weak negative correlation existed between the moisture content and feed rate.

To obtain the feed rate value only given the moisture content the following regression linear correlation general formula was used:

$$
\mathrm{Y}=\mathrm{a}+\mathrm{X} \_2 \mathrm{~b}
$$

Where: $\mathrm{Y}-$ feed rate

X_2 -Moisture content

And $\mathrm{a}$ and $\mathrm{b}$ - are constants

Where

$$
\mathrm{a}=11.6
$$

and

$$
b=-0.0713
$$

Hence the correlation formula was:

$$
\mathrm{Y}=11.6-0.0713 \mathrm{X} \_2
$$

Determination of correlation between particle size and feed rate

Particle size against feed rate.

\begin{tabular}{ll}
\hline (Ps) particle size $(\mathbf{m m})\left[\mathbf{x}_{\mathbf{3}}\right]$ & (fr) feed rate $(\mathbf{r e v} / \mathbf{m i n})[\mathbf{y}]$ \\
\hline 0.8 & 10.9 \\
1.0 & 12.2 \\
0.8 & 9.4 \\
0.95 & 10.9 \\
0.8 & 11.0 \\
0.8 & 10.5 \\
1.0 & 10.6 \\
\hline
\end{tabular}

\begin{tabular}{ll}
\hline 0.8 & 11.5 \\
0.9 & 12.4 \\
1.0 & 11.3 \\
0.95 & 11.2 \\
1.2 & 11.25 \\
0.8 & 11.6 \\
1.0 & 11.1 \\
0.8 & 11.8 \\
1.0 & 11.32 \\
0.95 & 11.2 \\
0.8 & 11.4 \\
$\sum \mathrm{x}_{3}=14.4$ & $\sum \mathrm{y}=201.57$ \\
\hline
\end{tabular}

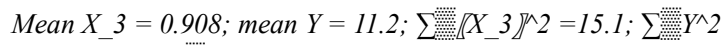

$=2264 . \overline{6849} ; \sum_{\text {w. }}\left[X X_{-} 3 Y\right]=183.295 ; s_{-}\left(X_{-} \overline{3}\right)=0.115$ and $s_{-} Y=0.66$

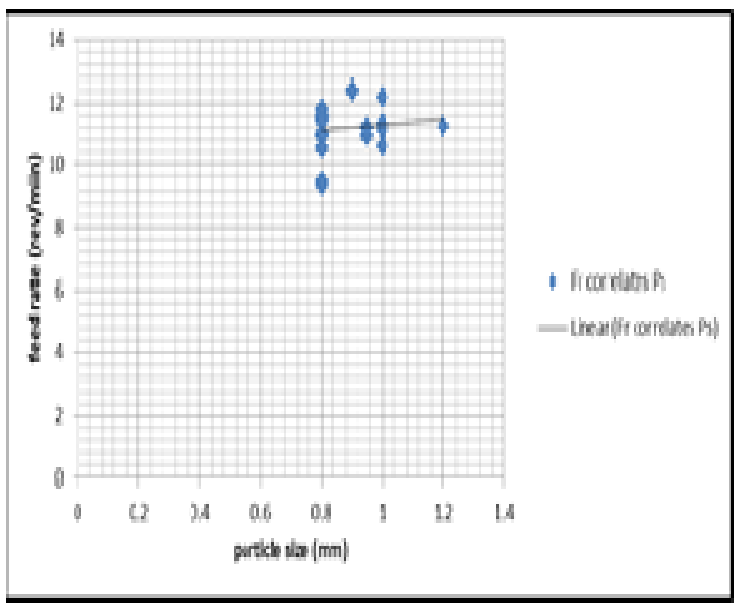

Figure 5. Correlation between particle size and feed rate

$$
\begin{gathered}
\mathrm{r}=\mathrm{s} \_x y /\left(\mathrm{s} \_x \text { s_y }\right) \\
\mathrm{r}=0.011236111 /((0.115 * 0.66)) \\
\mathrm{r}=0.1563 \text { s.f. }
\end{gathered}
$$

The coefficient correlation between moisture particle size and feed rate was 0.156 , and therefore a weak positive correlation existed between the particle size and feed rate.

To obtain the feed rate value only given the particle size the following regression linear correlation general formula was used:

$$
\mathrm{Y}=\mathrm{a}+\mathrm{X} \_3 \mathrm{~b}
$$

Where: $\mathrm{Y}$ - feed rate (Fr) in rev/min X_2 - Particle size (Ps) in $\mathrm{mm}$

And $\mathrm{a}$ and $\mathrm{b}$ - are constants

Where

$$
\mathrm{a}=10.4
$$

and

$$
b=0.894
$$

Hence the correlation formula is: 


$$
\mathrm{Y}=10.4+0.894 \mathrm{X} \_3
$$

The overall extrusion calculator operating formula was obtained by the addition of the equation 1,2 and 3 as highlighted below:

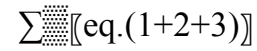

$$
\begin{aligned}
& \mathrm{Y}=10.1+0.199 \mathrm{X} \_1 \\
& \mathrm{Y}=11.6-0.0713 \mathrm{X} \_2 \\
& \mathrm{Y}=10.4+0.894 \mathrm{X} \_3 \\
& \rightarrow 3 \mathrm{Y}=32.1+0.199 \mathrm{X} \_2-0.0713 \mathrm{X} \_2+0.894 \mathrm{X} \_3
\end{aligned}
$$

Dividing by 3 both sides of the equation;

$$
\rightarrow \mathrm{Y}=0.0663 \mathrm{X} \_1-0.0238 \mathrm{X} \_2+0.298 \mathrm{X} \_3+10.7
$$

\begin{tabular}{|c|c|c|c|c|c|c|}
\hline$X_{1}(\%)$ & $\mathbf{X}_{2}(\%)$ & $\mathbf{X}_{\mathbf{3}}(\mathbf{m m})$ & $\mathrm{Y}(\mathrm{rev} / \mathrm{min})$ & $\begin{array}{l}\mathbf{Y}_{\text {1) }}{ }_{\text {cal(rev / }} \\
\text { min) }\end{array}$ & $\mathbf{Y}-\mathbf{Y}_{\text {cal }}$ & $\left(\mathrm{Y}-\mathrm{Y}_{\mathrm{cal}}\right.$ \\
\hline 5.101 & 5.182 & 0.8 & 10.9 & 11.2 & -0.3 & 0.09 \\
\hline 6.220 & 5.954 & 1.0 & 12.2 & 11.3 & 0.9 & 0.81 \\
\hline 4.800 & 5.627 & 0.8 & 9.40 & 11.1 & -1.7 & 2.89 \\
\hline 7.000 & 4.893 & 0.95 & 10.9 & 11.3 & -0.4 & 0.16 \\
\hline 5.261 & 5.830 & 0.8 & 11.0 & 11.1 & -0.1 & 0.01 \\
\hline 4.901 & 5.232 & 0.8 & 10.5 & 11.1 & -0.6 & 0.36 \\
\hline 6.250 & 6.301 & 1.0 & 10.6 & 11.3 & -0.7 & 0.49 \\
\hline 4.728 & 5.659 & 0.8 & 11.5 & 11.1 & 0.4 & 0.16 \\
\hline 5.635 & 4.496 & 0.9 & 12.4 & 11.2 & 1.2 & 1.44 \\
\hline 6.452 & 6.033 & 1.0 & 11.3 & 11.3 & 0 & 0 \\
\hline 5.312 & 6.980 & 0.95 & 11.2 & 11.2 & 0 & 0 \\
\hline 6.670 & 6.073 & 1.2 & 11.25 & 11.4 & -0.15 & 0.0225 \\
\hline 5.784 & 6.123 & 0.8 & 11.6 & 11.2 & 0.4 & 0.16 \\
\hline 6.342 & 6.032 & 1.0 & 11.1 & 11.3 & -0.2 & 0.04 \\
\hline 5.476 & 6.062 & 0.8 & 11.8 & 11.2 & 0.6 & 0.36 \\
\hline 6.338 & 5.686 & 1.0 & 11.32 & 11.3 & 0.02 & 0 \\
\hline 6.360 & 6.228 & 0.95 & 11.2 & 11.3 & -0.1 & 0.01 \\
\hline \multirow[t]{2}{*}{4.877} & 5.312 & 0.8 & 11.4 & 11.1 & 0.3 & 0.09 \\
\hline & & & & & & 7.0925 \\
\hline
\end{tabular}

Therefore the extrusion operation formula was:

$$
\mathrm{Y}=0.0663 \mathrm{X} \_1-0.0238 \mathrm{X} \_2+0.298 \mathrm{X} \_3+10.7
$$
low:

Testing the formula to the following result variables be-

Testing the calculator formula and determining its errors.

Note: all the rows with bold grey coloured digits represent were good chunks were produced. where $Y \rightarrow$ actual feed rate, $Y_{-}$cal $\rightarrow$ calculated feed rate; and $\left(Y-Y \_\right.$cal $) \rightarrow$ error.

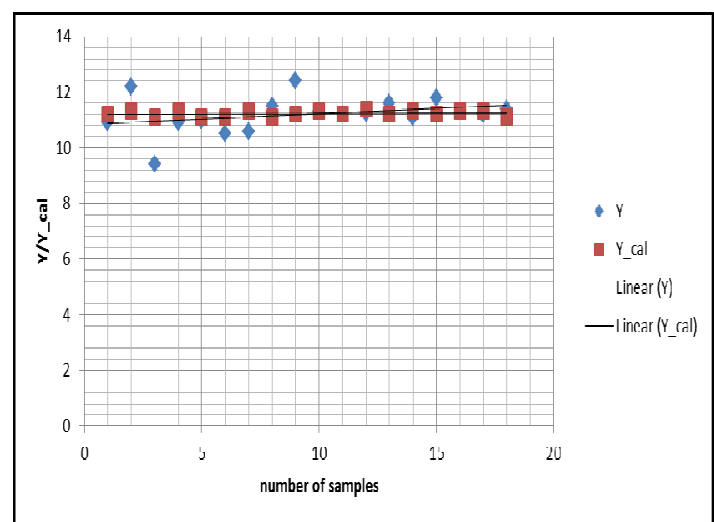

Figure 6. Correlation between actual feed rate $(Y)$ and calculated feed rate (Y_cal)

The summation of errors:

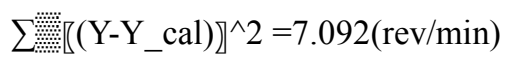

Considering the trend of the results, the formula was much more applicatory were good and excellent chunks were processed. The degree to which the formula was applicatory:

average error of success

$$
\begin{aligned}
& = \pm \sqrt{ }\left(\left(\sum \text { W. } \llbracket\left(Y-Y_{-} \text {cal }\right) \searrow \wedge 2\right) / \mathrm{n} \mathrm{rev} / \mathrm{min}\right) \\
& = \pm \sqrt{ }(1.5325 / 9) \mathrm{rev} / \mathrm{min} \\
& = \pm 0.4 \mathrm{rev} / \mathrm{min}
\end{aligned}
$$

Hence the approximation error to the formula to obtain good or excellent chunks was $\pm 0.4 \mathrm{rev} / \mathrm{min}$.

Summary of the operating formula of the extrusion calculator

$$
\mathrm{Y}=0.0663 \mathrm{X} \_1-0.0238 \mathrm{X} \_2+0.298 \mathrm{X} \_3+10.7
$$

at an error of

$$
\pm 0.4 \mathrm{rev} / \mathrm{min}
$$

Where

$$
\begin{gathered}
\text { X_1 } \rightarrow \text { Fat content }(\%), \\
X \_2 \rightarrow \text { Moisture content (\%), } \\
\text { X_3 } \rightarrow \text { Particle size (mm) }
\end{gathered}
$$

and

$$
\mathrm{Y} \rightarrow \text { Calculated feed rate (rev/min) }
$$

This formula was encoded in the program operating on the extrusion calculator. This extrusion calculator satisfies the following conditions for extrusion cooking process to be successful:

fat content $\geq 6.0 \%$

moisture $<6.0 \%$ 
particle size should be between 0.95 and $1.0 \mathrm{~mm}$

Extrusion Calculator Feed Property Operating Ratios

The formula that was obtained above was restricted to the calculation of feed rate depending on the feed property conditions; therefore for an effective extrusion process these conditions were supposed to be met. Not all of the produced soy meal contained a fat content above $6.0 \%$ and moisture content less than the fat content hence to satisfy all conditions operating ratios to the formula were obtained.

\begin{tabular}{llll}
\multicolumn{5}{c}{ Estimated mixing ratios to meet the condition $F c \geq 6.0 \%$} \\
\hline $\begin{array}{l}\text { Sample } \\
\text { Selection }\end{array}$ & $\begin{array}{l}\text { Fc (\%) for soy } \\
\text { meal A }\end{array}$ & $\begin{array}{l}\text { Fc (\%) for soy Ratio mixing } \\
\text { meal B }\end{array}$ & \begin{tabular}{l} 
Factors (fca:fcb) \\
\hline 1
\end{tabular} \\
\hline $4.5-4.8$ & $7.2-7.5$ & $0.25: 0.645$ \\
& $4.9-5.2$ & $7.2-7.5$ & $0.25: 0.645$ \\
& $5.3-5.6$ & $7.2-7.5$ & $0.25: 0.645$ \\
& $4.5-4.8$ & $6.7-7.0$ & $0.512: 0.529$ \\
& $4.9-5.2$ & $6.7-7.0$ & $0.512: 0.529$ \\
& $5.3-5.6$ & $6.7-7.0$ & $0.512: 0.529$ \\
& $4.5-4.8$ & $6.3-6.6$ & $0.210: 0.766$ \\
& $4.9-5.2$ & $6.3-66$ & $0.210: 0.766$ \\
& $5.3-5.6$ & $6.3-66$ & $0.210: 0.766$ \\
\hline
\end{tabular}

From the table above the ratios were calculated using the possible situations that are likely to arise during production. The ratios above were calculated from the procedures that follow:

Sample selection 1:

Assumption:

\begin{tabular}{llll}
\hline & Soy meal A & Soy meal B & Required \\
\hline Fat content (\%) & 4.5 & 7.5 & 6.0 \\
\hline
\end{tabular}

$$
4.5 \mathrm{a}+7.5 \mathrm{~b}=6.0
$$

Where $\mathrm{a}$ and $\mathrm{b}$ were the ratio mixing constants; and assuming that there is similar condition within the range of:

\begin{tabular}{llll}
\hline & Soy meal A & Soy meal B & Required \\
\hline Fat content & 4.75 & 7.4 & 6.0 \\
\hline Therefore, & & &
\end{tabular}

$$
4.75 a+7.4 b=6.0
$$

Combining the equation (1) and (2)

$$
a=(6.0-7.5 b) / 4.5
$$

Substituting a eq. 2 with that in eq. 3

$$
\begin{gathered}
4.75(6.0-7.5 b)+33.3 b=27 \\
b=0.6453 \text { s.f. }
\end{gathered}
$$

And hence,

$$
a=(6.0-7.5(0.645)) / 4.5
$$

Therefore

$$
a=0.2583 \text { s.f. }
$$

The obtained mixing ratio of $0.258: 0.645$ was tested through all the possible fat content outputs that might arise in sample selection 1 .

Sample selection 2:

An assumption that there was a soy meal with a fat content of $4.5 \%$ and another with $7.0 \%$ and were supposed to be mixed to meet the required $6.0 \%$ of fat content.

$$
4.5 \mathrm{a}+7.0 \mathrm{~b}=6.0
$$

And an assumption of a similar condition within the range of having soy meal with a fat content of $4.8 \%$ and another with $6.7 \%$ was, therefore

$$
4.8 \mathrm{a}+6.7 \mathrm{~b}=6.0
$$

Combining the equation (1) and (2)

$$
a=(6.0-6.7 b) / 4.8
$$

Substituting a in eq. 3 into eq. 1

$$
\begin{gathered}
4.5(6.0-6.7 b)+33.6 b=28.8 \\
b=0.5293 \text { s.f. }
\end{gathered}
$$

And hence

$$
\mathrm{a}=(6.0-6.7(0.529)) / 4.8
$$

Therefore

$$
\mathrm{a}=0.512 \text { 3s.f. }
$$

The obtained mixing ratio of 0.529:0.512 was tested through all the possible fat content outputs that might arise in sample selection 2 .

\section{Sample selection 3:}

Assumption

\begin{tabular}{llll}
\hline & Sample A & Sample B & Required \\
\hline Fat content (\%) & 4.5 & 6.6 & 6.0 \\
\hline
\end{tabular}

For such a combination the possible formula obtained was:

$$
4.5 a+6.6 b=6.0
$$

Where $\mathrm{a}$ and $\mathrm{b}$ were the ratio mixing constants; and assuming that there is similar condition within the range of:

\begin{tabular}{lll}
\hline Sample A & Sample B & Required \\
\hline 5.6 & 6.3 & 6.0 \\
\hline
\end{tabular}

Therefore

$$
5.6 a+6.3 b=6.0
$$

Combining the equation (1) and (2)

$$
a=(6.0-6.6 b) / 4.5
$$

Substituting a in eq. 3 into eq. 2

$$
5.6(6.0-6.6 b)+28.35 b=27.0
$$$$
b=0.7663 \text { s.f. }
$$ 
And hence

$$
\mathrm{a}=(6.0-6.6(0.766)) / 4.5
$$

Therefore

$$
\mathrm{a}=0.2103 \mathrm{~s} . \mathrm{f} \text {. }
$$

The obtained mixing ratio of 0.210:0.766 was test through all the possible fat content outputs that might arise in sample selection 3.

After obtaining the ratio of mix, the calculated fat content and the blended moisture content are to be fed in the extrusion calculator to obtain the overall feed rate of the soy meal.

\section{Discussion}

The design of the extrusion calculation as an implementation procedure was built on the basis of the data obtained from the results. Because of such analysis of the trends, a formula was formulated to promote maximum extrusion and an error of deviation of $\pm 0.4 \mathrm{rev} / \mathrm{min}$ was obtained and it must be accounted for at all cases. The formula which was obtained from the analysis of the results data was used to come up with a program that is currently running on the calculator. The extrusion calculator was designed to meet the needs at Monmouth Path Investments and to eliminate the error of extrusion failure. The application of the extrusion calculator and ratio mixing chart were implemented to increase the general soy meal/chunk conversion from $65 \%$ to $80 \%$.

\section{Conclusion}

The research was done and some of its objectives were met. The objective of determining the effects of feed properties on extrusion cooking process was achieved. Following the results, the objective of determining the effects of feed properties on extrusion process, the best conditions of these feed properties to satisfy an effective extrusion process were achieved. These conditions were: the soy meal must have fat content of greater than $6.0 \%$, moisture content of less than $6.0 \%$ and the soy meal must have a particle size of $0.8-$ $1.0 \mathrm{~mm}$. The objective of increasing the soy meal/chunk conversion standard of $65 \%$ was met though the extent of increasing the standard up to $80 \%$ is not yet measurable. For the best extrusion cooking process, in the case of attaining an optimized-controlled extrusion cooking process, an extrusion calculator and a ratio mixing/bending chart were designed. The extrusion calculator assists in the calculation of the feed rate under the above mentioned conditions and the ratio mixing chart helps in obtaining the standard extrusion fat content of greater than or equal to $6.0 \%$.

\section{References}

[1] ASTM International - Standards Worldwide. (2006). ASTM C136-06. http://www.astm.org/cgi-bin/SoftCart.exe/DATABASE.CAR T/REDLINE_PAGES/C136.htm?E+mystore

[2] Leschonski, Kurt "Sieve Analysis, The Cinderella of Particle Size Analysis Methods?" Powder Technology, Elsevier Sequoiz S.A., Lausanne, 24 (1979)

[3] Harper, J.M. (1979). Food extrusion. Crit. Rev. Food Sci. Nut.

[4] Lusas, E. and Riaz, M. (1994). An introduction to extruders and extrusion principles. Extrusion Communiqué, 12/94, $9-34$.

[5] Westwood, K.T. (1994). Extrusion of brewers' hops. In: The Technology of Extrusion Cooking. Frame, N.D. (Ed), Blackie Academic \& Professional, London, pp.237-250.

[6] Richert, B.T., Hancock, J.D., Hines, R.H. and .Gugle, T.L. (1992). Extrusion processing of cereal

[7] J. Anim Grains and soybean meal for weanling pigs. Sci.www.extrusionfactors.edu/effects. $270000008 \mathrm{a} / \mathrm{htmlhttp}$ : //online.sfsu.edu/ jge/html/stdsinglestagexscrew.html

[8] J. J. Castillo (2009). Statistical Sampling Techniques. Retrieved 14 Mar. 2012 from Experiment Resources

[9] R. Groves, et alia. Survey methodology (2010) Second edition of the (2004) first edition

[10] D. S. Moore and G. P. McCabe (February 2005). "Introduction to the practice of statistics" (5th edition). W.H. Freeman \& Company. ISBN 0-7167-6282-X.

[11] F. David; P. Robert; P. Roger (2007). Statistics (4th ed.)

[12] L., Sharon L. (1999). Sampling: Design and analysis. Duxbury.

[13] Castells, M., Marin, S., Sanchis, V. \&Ramos, A.J. (2005). Fate of mycotoxins in cereals during extrusion cooking: a review. Food Additives and Contamination, 22, 150-157.

[14] Hauck, B.W. \& Huber, G.R. (1989). Single screw vs. twin screw extrusion. The American Association of Cereal Chemists, 34, 930-939.

[15] Bhandari, B., D'Arcy, B. \&Young, G. (2001). Flavour retention during high temperature short time extrusion cooking process: a review. International Journal of Food Science and Technology, 36, 453-461.

[16] Fellows, P. (2000). Food Processing Technology: Principles and Practice. Pp. 177-182. Cambridge: Wood head Publishing

Ltd.http://onlinelibrary.wiley.com/doi/10.1111/j.1365-2621. 2006.01309.x/full - b58

[17] Eastman, J., Orthoefer, F. \&Solorio, S. (2001). Using extrusion to create breakfast cereal products. Cereal Foods World, $46,468-471$

[18] Harper, J.M. (1989). Food extruders and their applications. In: Extrusion Cooking (edited by C.Mercier, P.Linko\&J.M.Harper). Pp. 1-16. St. Paul, MN: American Association of Cereal Chemists, Inc. 